\title{
Mismatch of Cultural Dimensions in an Urban Medical Educational Environment
}

\author{
Bethany Malone, Stephania Hasan, Aliu Sanni, and James Reilly \\ Department of Surgery, State University of New York, Downstate (Brooklyn Program), 451 Clarkson Avenue, Brooklyn, NY 11203, USA
}

Correspondence should be addressed to Bethany Malone; bethany.malone@downstate.edu

Received 29 May 2013; Accepted 3 September 2013

Academic Editor: Saeed Farooq

Copyright (C) 2013 Bethany Malone et al. This is an open access article distributed under the Creative Commons Attribution License, which permits unrestricted use, distribution, and reproduction in any medium, provided the original work is properly cited.

Objective. To identify cultural dimensions and their potential mismatches between attending physicians and their residents and medical students. Methods. We surveyed faculty and students, both undergraduates and postgraduate resident physicians, at the SUNY Downstate College of Medicine, using Hofstede's VSM-08 questionnaire, and calculated cultural dimensions, including the Power-Distance Index (PDI), Individualism (IDV), Masculinity (MAS), Uncertainty Avoidance Index (UAI), and Longterm Outlook (LTO). Correlations between faculty and student demographic data and cultural dimensions were calculated (SPSS). Results. There were 237 student and resident respondents and 96 faculty respondents. Comparing all faculty and student respondents, significant differences were found in four of five cultural dimensions, with faculty scoring higher in MAS, and lower in PDI, IDV, UAI, and LTO. Conclusions. These differences may be important in the design and implementation of a medical educational curriculum, and, particularly, in the measurement and evaluation of educational outcomes.

\section{Introduction}

The American healthcare system is confronted with numerous quantifiable problems such as rising demand, rapidly evolving technology, and high costs. Despite the potential improvements derived from technological advancement, attention has increasingly focused upon the less easily quantified "culture" of this healthcare system, which has often failed to meet fundamental requirements for accountability, effectiveness, and transparency. We believe that the "tip of the spear" in understanding and shaping the American healthcare "culture" may begin in the training and enculturation of our physicians within medical schools and graduate medical educational programs.

During the latter half of the 20th century, American society has become increasingly diverse, as immigrants to the United States have entered the country and integrated to varying degrees into the society. In New York City, nearly $40 \%$ of the population is foreign-born [1], and this diversity is reflected in virtually all aspects of urban life, including the healthcare system, where patients, the nonphysician workforce, and the physician workforce are increasingly foreignborn.
Many physicians and students enter the United States seeking medical education, and foreign-born physicians now comprise nearly $28 \%$ of all residents in ACGME-approved training programs [2]. These physicians in training interact with the largely indigenous American medical education system for physicians and also interact with the culturally diverse patient population that contributes to their educational experience. Cultural differences among these physicians in training may be influential, as they pursue their educational goals in the highly complex American health and educational system.

The quantitative measurement of culture in healthcare remains problematic. In their review, Scott et al. identified a range of instruments for measuring organizational culture in healthcare [3]. The choice of an instrument is influenced by the desirability of either a "typologic" approach, which assesses results based on holistic types of organizational cultures, or a "dimensional" approach, which assesses results based on identified characteristics of a culture. Of the available instruments, the dimensional approach of Hofstede's questionnaire, the Value Systems Module 2008, offered potentially the most insightful information in a relatively 
rapid and low-cost tool, and has historically been of use in the study of culture in higher education [4].

The description of cultural differences across nations has been pioneered by Hofstede, a sociologist who has studied the elements of national culture over the past 40 years [5]. Hofstede's interest in studying cultural differences arose from commercial interests, as American business entities sought to expand into European and far Eastern markets.

In 1967, IBM, as a large multinational corporation, began administering attitude surveys to employees of its various international subsidiaries. Rather than being a simple job satisfaction survey, the questionnaires included a substantial number of items asking about employees' basic values and beliefs. As employees were well-matched controls, having the same education and holding the same job within the same company while differing only in nationality, the IBM surveys were internationally standardized, creating a suitable tool for researching and measuring culture across nations. Hofstede used the IBM database to compare thousands of mean survey scores for identically stratified samples of employees in 40 countries [5]. From this extensive analysis, Hofstede and his colleagues identified several unique and fundamental dimensions by which a nation's culture can be described. His model has been validated by other sociology and political researchers [6]. Hofstede's cultural dimensions include the following.

(1) Power-distance (PDI), which measures the perception of stratification within a society, and the acceptance of that stratification by those within it.

(2) Individualism versus Collectivism (IDV), which describes the strength of ties between the individual and a group, which may be a family, tribe, ethnic group, or other social construct.

(3) Masculinity versus Feminity (MAS), which assesses the tendencies of a society to favor assertive behaviors as opposed to more modest behaviors. These behaviors manifest themselves in most cultures in the assignment of gender roles to its members. Male achievement and competitive behaviors are contrasted to female nurturing and concern for relationships and the living environment.

(4) Uncertainty Avoidance (UAI) measures the ability of a society to tolerate ambiguity or uncertainty, reflected in the society's desire for structure, rules and regulations, and order.

(5) These four basic cultural dimensions have been broadened to include other less well referenced characteristics, such as long-term orientation (LTO), societal indulgence, and monumentalism. These latter characteristics or dimensions can be gleaned from Hofstede's questionnaire, but their role in education and their plausible importance in healthcare are less clear. Our study will include the first four basic dimensions of culture, where these linkages are more secure, and include data on long-term orientation, which was also assessed in the questionnaire [7].
These cultural dimensions or tendencies are measured, not for individuals, but rather for groups, by analyzing patterns of response in a questionnaire [8]. This questionnaire, the Values Systems Module was updated in 2008 (VSM08), and it forms the basis for our project.

\section{Hypothesis}

We propose that measurable cultural characteristics, or dimensions, can be identified in the cadre of faculty and students (medical students and residents) in the particularly culturally diverse campus of the SUNY Downstate College of Medicine, in Brooklyn, NY. We believe that cultural differences between groups, such as faculty, residents, and medical students, may have important educational implications. We also hypothesize that cultural characteristics "survive" immigration to and education within the United States, perhaps over many years.

\section{Materials and Methods}

The Value Systems Module (VSM08) questionnaire consists of 35 multiple choice questions to which we have appended several questions to categorize medical students, residents, attending physicians, and faculty members and to identify the country of birth, age, and years of residence in the United States of study participants. No individual's identifying information, such as name and Social Security number, was elicited, in order to maintain confidentiality of study participants. The project was approved by the SUNY Downstate Institutional Review Board prior to execution. The questionnaire was administered to residents and medical students at the SUNY Downstate College of Medicine and to its faculty. The VSM08 questionnaire is structured to identify the above described cultural dimensions through specific answers to particular questions. Cultural dimensions were calculated from a Likert-like answer scale, and, using the VSM08 manual, scores for the four cultural dimensions were computed for each respondent, and then pooled for each relevant group. We compared cultural dimensions in a crosswise fashion between the faculty and the pooled data from two levels of students, resident physicians and medical students, stratifying these groups by native-born American and immigrant American citizens and noncitizens residents, gender, and age group.

Questionnaire results were tabulated in a passwordrestricted database (Access 07) and data was analyzed using statistical software (SPSS v 18.0). We compared mean values for faculty and students ( $t$-test), and correlated each cultural dimension with faculty or student (Pearson's $R^{2}$ ). For each cultural dimension, we applied multivariate analysis, using each cultural dimension as the dependant variable, and using faculty/student, age group, gender, and US birth as independent factors.

To assess the relative role of faculty status and US birth upon the cultural dimensions, we created dichotomous dummy variables for faculty or student status (student $=0$, faculty =1), and US birth categories (non-US birth $=0$, US birth $=1$ ) and we performed linear regression with each 


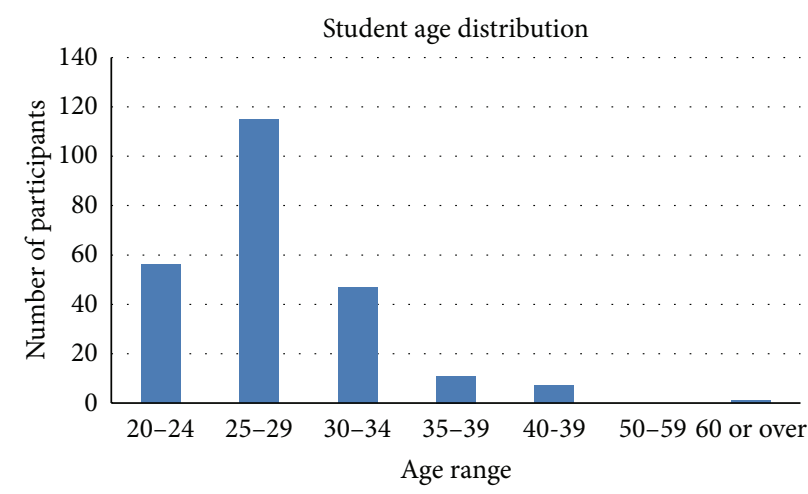

(a)

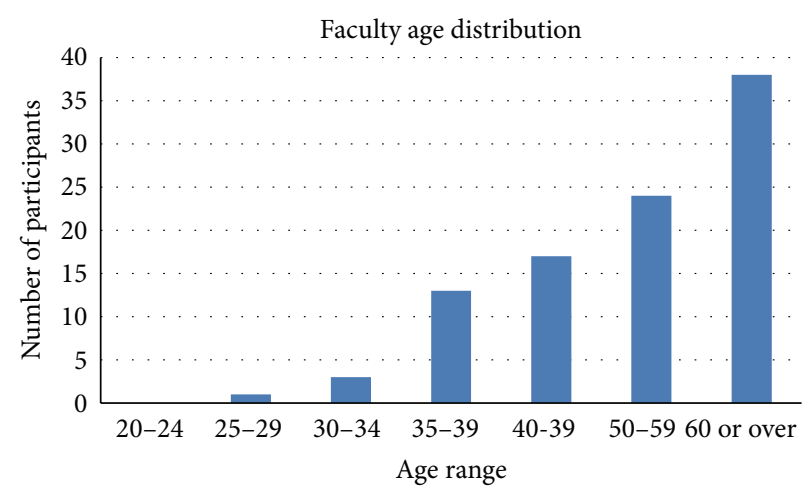

(b)

FIGURE 1: Age distributions of faculty and students.

TABLE 1: Quantification of cultural dimensions in faculty and students.

\begin{tabular}{lccc}
\hline Cultural dimension & Status & Mean & Sig. (2-tailed) \\
\hline \multirow{2}{*}{ Power Distance Index (PDI) } & Students & 157 & 145 \\
& Faculty & 113 & 0.022 \\
Individualism (IDV) & Students & 103 & 0.133 \\
& Faculty & 152 & 174 \\
Masculinity (MAS) & Students & 127 & 0.001 \\
& Faculty & 98.9 & 0.000 \\
Uncertainty Avoidance Index (UAI) & Students & 130 & 110 \\
\hline \multirow{2}{*}{ Long-Term Outlook (LTO) } & Faculty & & 0.003 \\
\end{tabular}

cultural dimension as the dependent variable, and the faculty and US birth dichotomous variables as independent variables. For each dimension, the $F$ statistic and $P$ value estimate the predictive power of the regression model, and the coefficients (sign and value) suggest the size and direction of each independent variable upon the cultural dimension, when the other variable is included.

\section{Results}

Of the 333 respondents, 237 were students and 96 were faculty at SUNY Downstate Medical Center. The majority (55\%) of faculty respondents were male, and $33 \%$ of faculty were foreign-born. In contrast, the majority of student respondents were female (55\%) and $28 \%$ of students were foreign-born. Immigrant student respondents listed 37 nations of birth, whereas non-US-born faculty respondents derived from 23 different countries. Faculty and students had distinctly different age distributions (Figure 1). There were no statistically significant differences between the two student levels, medical students and residents, in any of the mean cultural dimensions, and thus their data was pooled and then compared to the faculty.

We found statistically significant differences between faculty and student respondents in the mean values of four of Hofstede's five cultural dimensions (Table 1). Students scored higher in power-distance, uncertainty avoidance, and long-term outlook, while faculty scored higher in masculinity. No statistically significant difference was observed between faculty and students in individualism versus collectivism.

The correlations between each cultural dimension and a respondent parameter, including faculty status, age group, gender, and US birth are shown in Table 2. The Pearson correlation coefficient was statistically significant between age and MAS, UAI, and LTO, between gender and MAS, and between US Birth and PDI and IDV. Faculty status correlated with PDI, IDV, UAI, and LTO, but not MAS. While statistically significant, these correlations are not strong.

Regression analysis confirmed the statistically significant role that both faculty or student status and US birth have upon shaping the cultural profiles of the educational community at SUNY Downstate College of Medicine (Table 3). Faculty or student status played a more dominant role in determining both the masculinity-femininity dimension and the Uncertainty Avoidance dimension, while US birth more powerfully affected Power Distance and Individualism. Subset analysis of respondents by country was not performed, as there were not enough respondents from each country to provide a statistically meaningful analysis. 
TABLE 2: Correlation of cultural dimensions with age, gender, faculty, US birth, and years living in US.

\begin{tabular}{|c|c|c|c|c|c|}
\hline Cultural dimension & Age decade & Male gender & Faculty & US birth & Years in US \\
\hline \multicolumn{6}{|c|}{ Power Distance Index (PDI) } \\
\hline Pearson correlation $r$ & -0.073 & -0.010 & -0.127 & -0.120 & -0.075 \\
\hline Sig. (2-tailed) & 0.189 & 0.853 & 0.022 & 0.036 & 0.178 \\
\hline \multicolumn{6}{|l|}{ Individualism (IDV) } \\
\hline Pearson correlation $r$ & -0.055 & -0.045 & -0.082 & 0.162 & 0.040 \\
\hline Sig. (2-tailed) & 0.322 & 0.417 & 0.137 & 0.004 & 0.468 \\
\hline \multicolumn{6}{|l|}{ Masculinity (MAS) } \\
\hline Pearson correlation $r$ & 0.188 & 0.138 & 0.194 & -0.059 & -0.043 \\
\hline Sig. (2-tailed) & 0.001 & 0.013 & 0.000 & 0.302 & 0.444 \\
\hline \multicolumn{6}{|c|}{ Uncertainty avoidance index (UAI) } \\
\hline Pearson correlation $r$ & -0.202 & -0.084 & -0.211 & -0.056 & -0.065 \\
\hline Sig. (2-tailed) & 0.000 & 0.131 & 0.000 & 0.329 & 0.243 \\
\hline \multicolumn{6}{|l|}{ Long-Term Outlook (LTO) } \\
\hline Pearson correlation $r$ & -0.167 & 0.009 & -0.151 & -0.061 & 0.042 \\
\hline Sig. (2-tailed) & 0.002 & 0.866 & 0.006 & 0.291 & 0.449 \\
\hline
\end{tabular}

TABLE 3: Comparison of cultural dimensions between faculty and students and between US born and Non-US born respondents.

\begin{tabular}{lcccccc}
\hline \multirow{2}{*}{ Dependent Variable } & \multicolumn{2}{c}{ Model } & \multicolumn{4}{c}{ Independent Variables } \\
& F-Statistic & $P$ & \multicolumn{2}{c}{ Faculty (0) versus Student (1) } & \multicolumn{2}{c}{$\begin{array}{c}\text { Non-US Born (0) versus US Born (1) } \\
\text { Coefficient } B\end{array}$} \\
\hline PDI & 4.48 & 0.012 & -10.86 & 0.035 & -11.39 & 0.027 \\
IDV & 5.32 & 0.005 & -10.61 & 0.121 & 19.02 & 0.005 \\
MAS & 7.38 & 0.001 & 24.11 & 0.000 & -5.57 & 0.389 \\
UAI & 7.22 & 0.001 & -27.33 & 0.000 & -8.89 & 0.231 \\
LTO & 3.50 & 0.032 & -17.50 & 0.016 & -8.52 & 0.236 \\
\hline
\end{tabular}

\section{Discussion}

Defining culture in any social group is often difficult. According to Schein [9],

"Organizational culture is the pattern of shared basic assumption-invented, discovered, or developed by a given group as it learns to cope with its problems of external adaptation and internal integration - that has worked well enough to be considered valid, and therefore, to be taught to new members as the correct way to perceive, think, and feel in relation to those problems."

During the past 20 years, national borders have become more permeable, allowing freer trade of raw materials and manufactured goods, currency, and especially people. Largescale immigration has placed substantial economic, political, and social stress upon societies, particularly in Western Europe and the United States, which have received the bulk of immigrant flow [10]. As immigrants established families in their new homes, their children enter the schools, often straining budgets and the local educational culture.

The general high quality of American education has also encouraged the immigration of students, especially from the Far East, seeking higher-level college and graduate school degrees [11]. In California, nearly one in four college graduate level students are foreign-born students [12].

In American healthcare, foreign-born students comprise a substantial and rising proportion of postgraduate residency trainees [13]. Admitted to the United States on temporary educational visas, they are anticipated to return to their home country after completing their training, but many remain and begin practicing throughout the United States, either under extended visas or as naturalized citizens. Currently, foreign medical graduates comprise $50 \%$ of all resident training slots [13], and foreign medical graduate physicians comprise $25 \%$ of the American physician workforce [13].

The SUNY Downstate College of Medicine, located in Brooklyn, New York, is a unique educational environment. The medical school is located in a borough of New York City long recognized for its diversity. Brooklyn has been a destination for numerous immigrant groups, and in recent decades, the neighborhoods adjoining the medical school have seen an influx from the Caribbean, West Africa, Southern Asia, and South America. These immigration patterns are reflected in the staff of two nearby hospitals, the University Hospital of Brooklyn, and the Kings County Hospital Center, both public safety net hospitals.

At the Downstate College of Medicine, over $40 \%$ of the medical students are foreign-born, and approximately $30 \%$ of the clinical and the medical school faculty are 
foreign-born [14]. In this culturally diverse higher-level education system, issues related to governance, planning, curriculum development and design, student selection, and student evaluation may be influenced by, and experience tension due to, the diversity of attitudes and beliefs of both faculty and students as they interact in the educational process.

Our study found significant differences between faculty and students in four of Hofstede's five major cultural dimensions. The first, Power-Distance (PDI), reflects the presence of power and prestige within a social construct, such as a medical school, and, importantly, the acceptance of such stratification by those within it [15]. Within an American physician training program, such as a surgical residency, hierarchical structures define attending physicians (teachers) and residents (students), and resident hierarchies are defined by PGY years. Students culturally acclimatized to a highpower distance educational environment are typically subservient to teachers, prefer structured educational plans, and meet defined educational goals. In low-power distance educational environments, teachers and students have more collaborative and less structured relationships, and students are encouraged to individualize their educational trajectory [16]. A cultural mismatch between a resident or student and the educational environment may produce poor academic performance, and a faculty perception that the resident is underachieving [17]. Physician-patient interactions may also be impaired by power distance mismatches, where disparities between patients and physicians in education, social status, and income are commonplace. Physicians with lower power distance expectations may seek more collaborative interactions with their patients, while those with high-power distance expectations may adopt more paternalistic or authoritarian approaches towards patients. In either case, a cultural mismatch in this realm may produce ineffective patient care and dissatisfaction by both physician and patient within the physician patient relationship.

We also found differences between faculty and students in the Individualism versus Collectivism (IDV) dimension. In highly individualistic societies, ties between individuals are relatively loose, and individuals are expected to look after themselves and their immediate families. In highly collectivist societies, individuals are integrated into a strong, cohesive in-group from birth, which offers protection in exchange for unquestioning loyalty throughout an individual's lifetime. Across the globe, the vast majority of individuals live in collectivist societies where the interests of the group supersede those of its individual members. In collectivist societies, education is typically teacher-centered and focuses upon acquiring knowledge and skills necessary for group membership. In terms of medical education, students and residents from such societies may focus upon meeting requirements for graduation or board certification. In contrast, an individualist society's education focuses on learning how to learn, and especially how to cope with the unknown, and with new, unforeseen circumstances. Diplomas or certificates are valued by individualistic societies as demonstrations of personal accomplishment and self-respect; in collectivist societies, they entitle the holder to membership in a higher status group. Physicians from an individualist society may interact with patients as individuals, be less inclined to involve family or other group members in patient care, and may participate in a multidisciplinary care team less effectively.

Faculty scored higher than students in the Masculine versus Feminine (MAS) dimension. In strongly assertive or masculine cultures, value is placed upon earnings, recognition, advancement, and challenge [18]. In contrast, more modest or feminine cultures value strong working relationships with others, cooperation, and employment security. Within the American healthcare system, gender roles are often rigid; most nurses are female. While females have been entering the physician ranks for decades, relatively few have risen to positions of academic leadership, and within specialties such as surgery, a persistent masculine culture may be perceived as a barrier to success for female surgeons. Immigrant physicians from strongly masculine or assertive cultures may experience difficulty in adjusting to the increasing feminine presence among the American physician cadre, particularly when placed in a subordinate role to a supervising female resident or attending.

Uncertainty avoidance (UAI) measures the ability of a group to tolerate ambiguity or uncertainty, which generates social anxiety, an inevitable condition that different cultures accommodate differently. In uncertainty intolerant cultures, educational systems stress the role of the teacher as expert, create clear roles and job descriptions in the workplace, and place high social value upon achieving anticipated results. Within the American medical education system, students may experience cultural disorientation as the progress from the typically highly structured initial years of medical school to the far less structured final clinical clerkship phase. Many post-graduate residency programs provide clinical experiences for learning, which are highly unstructured ("Let's see what comes in through the emergency room"), and students from cultures with low uncertainty tolerance may find this lack of the structure unsettling.

Almost by definition, in a medical school, faculty are older than students, and this is reflected in the strong correlation between faculty status and age group (Pearson correlation coefficient $0.833, P=0.000$ ). Certainly, some of our observed differences in cultural dimensions may be strongly influenced by age rather than other descriptors of our study groups.

Our foreign-born faculty and students are themselves extremely heterogeneous. Faculty immigrated to the United States from 23 different countries, while students immigrated from 37 countries. Each country has its own distinct culture with characteristic patterns of each dimension, and blending them into a single group of non-US-born study subjects, as does our study, invariably produces blurring of the statistical data, as specificity is lost by aggregation, and important distinctions may be lost when the group is compared to the presumably more homogenous US-born cadre.

A potential limitation of the study is generalizability to medical institutions in other urban centers or in more rural settings. As interviewers of prospective medical students and residents are aware of the diversity of the Brooklyn community, they may be more likely to accept applicants from 
a higher variety of ethnic, cultural, and national backgrounds in order to mirror the composition of the patient population. Additionally, faculty from different backgrounds may be attracted to work in a community that reflects the cultures and values from which they came. While the more homogenous results for medical students and residents enabled these groups to be combined statistically, there is no longitudinal aspect to the study, which would reveal whether medical education inherently acculturates individuals in terms of PDI, IDV, MAS, UAI, and LTO. Performing the study in other medical centers and adding a longitudinal component, such as assessment upon application to medical school, residency, or faculty position, followed by a reassessment after completing a portion of study would elucidate these matters. There is also no comparison between surgical faculty and general medical faculty, which may show that surgical faculty are more likely to possess certain cultural characteristics when compared to faculty in other specialties. Another unanswered question is whether this cultural mismatch is unique to trainees in the United States, or if these differences exist for immigrants to other countries. Are programs that attract international applicants culturally similar to each other and dissimilar from their international applicants?

Our study raises questions for further study. While residents and medical students were examined before being combined into a fairly homogenous group, no such evaluation was completed for faculty members. Do younger faculty differ from older faculty, which may lead to less cultural mismatch between faculty and students in the future if age is also related to Hofstede's cultural dimensions? Are Hofstede's cultural dimensions shaped, not only by the individual's culture of origin, but by the experience of emigration, and if so, in what ways, and how rapidly? Do native cultural dimensions influence the decision to emigrate to another cultural setting to seek educational or career opportunities? Are US-born students and faculty culturally homogenous, or do other factors such as ethnicity affect cultural dimensions or participants from the same country of origin? How does physician "culture" interact with Hofstede's cultural dimensions, and does the cultural "fit" of a specific cultural heritage influence specialty choice, practice style, or any other measures of the physician educational effort in American medical schools? How do physicians' cultural dimensions compare to the cultural dimensions of other healthcare workers, specifically, nurses? While this study does address cultural dimensions, it does not quantify the degree of enculturation or time spent by trainees and attending physicians in the United States healthcare education system. Foreign-born attendings may differ from foreign-born trainees simply because they have spent more time being acculturated to the US system. In addition, we have no measures of patient perceptions and satisfaction with foreign-born trainees, or whether foreign-born trainees differ culturally from the immigrant-rich patient population in Brooklyn.

Fifty years ago, Samuel Bloom, an anthropologist, conducted a study of the interactions between faculty and students at the SUNY Downstate College of Medicine. Published as: "Power and Dissent in the Medical School," Bloom's work highlighted distinct divergent core beliefs about the medical school's mission, governance, and functioning between faculty and students [19]. Then, Downstate was a young medical school founded only a decade earlier, and its faculty and student composition reflected that of the 1960s, Brooklyn. Both faculty and students were predominantly white, and while the faculty was drawn from a geographically diverse pool of academics, the students were far more homogenous, with the vast majority native to the environs of New York City. Bloom found little expression of racial or ethnic roots in the disputes that he observed between faculty and students, which were centered primarily over issues of role and purpose [19]. Our study results identify significant cultural differences between faculty and students, but consider them through a different lens of sociologic research.

The College of Medicine at Downstate has changed considerably over the half-century since Bloom's report. Most noticeably, the neighborhood surrounding the campus is now primarily black, dominated by two decades of continued Caribbean-African immigration, and Brooklyn itself has ethnically become predominantly black, but with a mix of African-American and immigrant cultures. The medical school has similarly evolved, with a student body comprised of nearly $40 \%$ foreign-born students, with even more firstgeneration American-born students of immigrant families from Central and Latin America, the Caribbean, East Asia, and the Far East. The faculty is similarly diverse.

Our study shows a significant difference in four of the five cultural dimensions studied. This may explain the marked differences between the students and faculty at different times in their career. Also, it may show important differences between students from diverse cultural backgrounds as it pertains to their general attitude. A medical student from a cultural background with high-power distance might be considered timid, while one from a low-power distance background would be considered outspoken. This should be borne in mind during evaluation of medical students.

Defining culture, a difficult task, is far less difficult than the challenges faced in attempting to understand the why of a culture, and then to change it. If the challenges facing American healthcare demand cultural change, we believe such change will emerge most rapidly and effectively by an educational system in which new physicians are effectively enculturated to the values, attitudes, and behaviors best suited to address those challenges.

\section{Conclusion}

Statistically significant differences between faculty and students at SUNY Downstate Medical Center were discovered for four out of five of Hofstede's cultural dimensions. Faculty scored higher in masculinity, while students scored higher in power-distance, uncertainty avoidance, and long-term outlook. No statistically significant difference was observed in individualism versus collectivism. When accounting for age, gender, faculty/student status, US birth, and number of years spent in the US; faculty or student status was most strongly correlated with masculinity-femininity and uncertainty avoidance, while US birth correlated with power distance and individualism. Age, gender, and number of years 
spent in the US showed no statistically significant correlation with Hofstede's cultural dimensions.

\section{Conflict of Interests}

The authors of this paper used commercial SPSS $\mathrm{v} 18.0$ software for statistical analysis of the data. The authors have no commercial interests and have received no financial or other compensations by the manufacturers of this software.

\section{References}

[1] New York City Department of City Planning, "The newest New Yorkers 2000: immigrant New York in the new millenium,"October 2004, http://www.nyc.gov/html/dcp/pdf/census/nny_briefing_booklet.pdf.

[2] American Medical Association, IMG Section Governing Council, "International medical graduates in American medicine: contemporary challenges and opportunities," January 2010, http://www.ama-assn.org/ama1/pub/upload/mm/18/imgworkforce-paper.pdf.

[3] T. Scott, R. Mannion, H. Davies, and M. Marshall, "The quantitative measurement of organizational culture in health care: a review of the available instruments," Health Services Research, vol. 38, no. 3, pp. 923-945, 2003.

[4] S. Manikutty, N. S. Anuradha, and K. Hansen, "Does culture influence learning styles in higher education?" International Journal of Learning and Change, vol. 2, pp. 70-87, 2007.

[5] G. Hofstede, Culture's Consequences: International Differences in Work-Related Values, Sage Publications, Beverly Hills, Calif, USA, 1980.

[6] Chinese Culture Connection, "Chinese values and the search for culture-free dimensions of culture," Journal of Cross-Cultural Psychology, vol. 18, no. 2, pp. 143-164, 1987.

[7] G. Hofstede and M. H. Bond, "The Confucius connection: from cultural roots to economic growth," Organizational Dynamics, vol. 16, no. 4, pp. 5-21, 1988.

[8] G. Hofstede, A. V. Garibaldi de Hilal, S. Malvezzi, B. Tanure, and H. Vinken, "Comparing regional cultures within a country: lessons from Brazil," Journal of Cross-Cultural Psychology, vol. 41, no. 3, pp. 336-352, 2010.

[9] E. Schein, Organizational Culture and Leadership, Jossey-Bass, San Francisco, Calif, USA, 1985.

[10] A. Shah, "Immigration," Global Issues, May 2008, http://www .globalissues.org/article/537/immigration.

[11] P. Chow, What International Students Think about U.S. Higher Education: Attitudes and Perceptions of Prospective Students in Africa, Asia, Europe and Latin America, Institute of International Education (IIE), New York, NY, USA, 2011.

[12] H. Johnson, "Immigrants and education," Public Policy Institute of California, 2011, http://www.ppic.org/main/publication show.asp? $\mathrm{i}=821$.

[13] American Medical Association, IMG Section Governing Council, "International medical graduates in American medicine: contemporary challenges and opportunities," January 2010, http://www.ama-assn.org/amal/pub/upload/mm/18/img-workforce-paper.pdf.

[14] Office of the Dean, Personal Communication, SUNY-Downstate College of Medicine, Brooklyn, NY, USA, 2010.
[15] G. Hofstede, Culture's ConSequences: Comparing Values, Behaviors, Institutions and Organizations across Nations, Sage Publications, Thousand Oaks, Calif, USA, 2nd edition, 2001.

[16] G. Hofstede and R. R. McCrae, "Personality and culture revisited: linking traits and dimensions of culture," Cross-Cultural Research, vol. 38, no. 1, pp. 52-88, 2004.

[17] K. Klein, F. Dansereau, and R. J. Hall, "Level issues in theory development, data collection, and analysis," Academy of Management Review, vol. 19, pp. 195-229, 2004.

[18] G. Hofstede, B. Neuijen, D. D. Ohayv, and G. Sanders, "Measuring organizational cultures: a qualitative and quantitative study across twenty cases," Administrative Science Quarterly, vol. 35, no. 2, pp. 286-316, 1990.

[19] S. Bloom, Power and Dissent in the Medical School, Free Press, New York, NY, USA, 1973. 

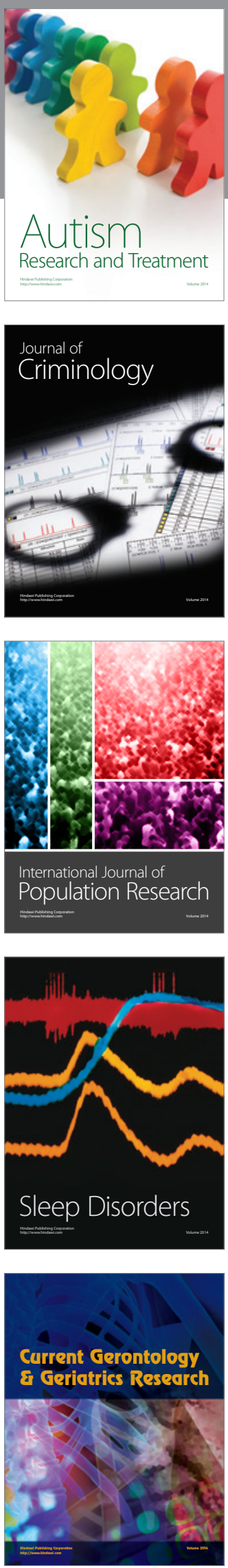
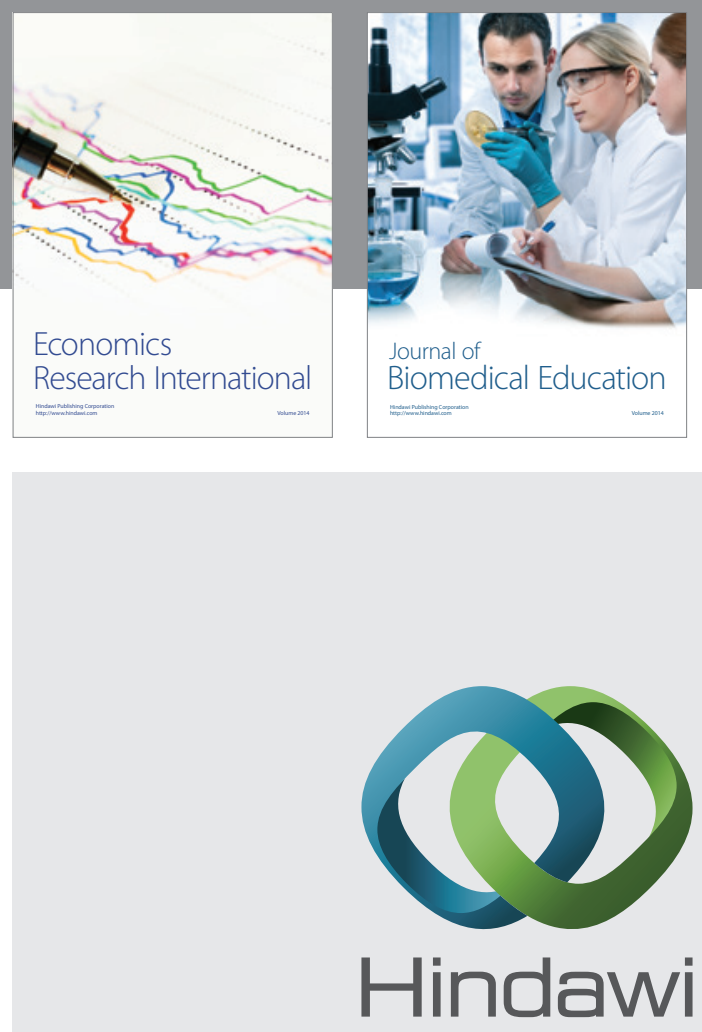

Submit your manuscripts at

http://www.hindawi.com
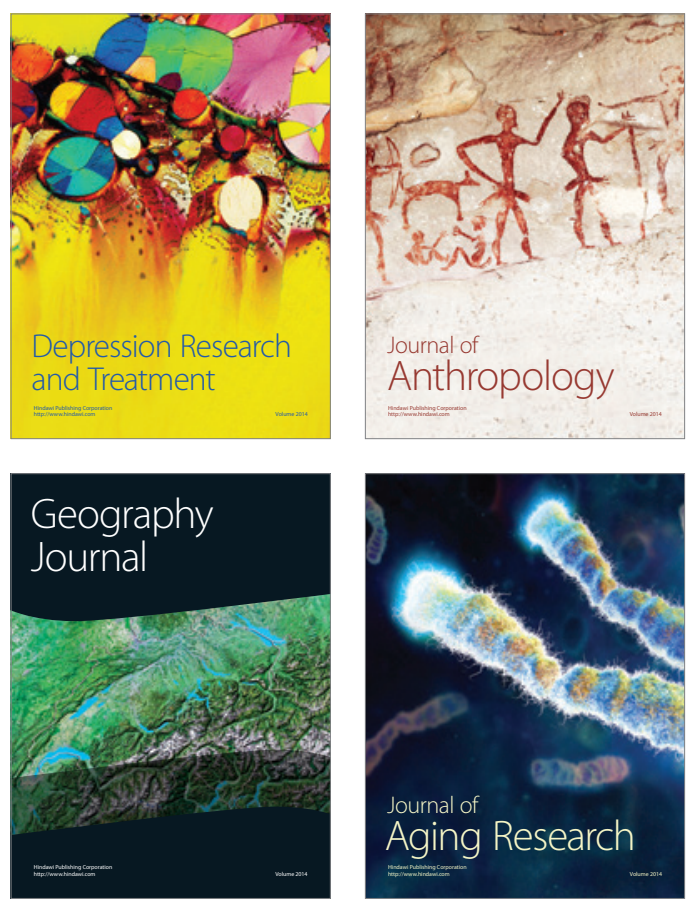
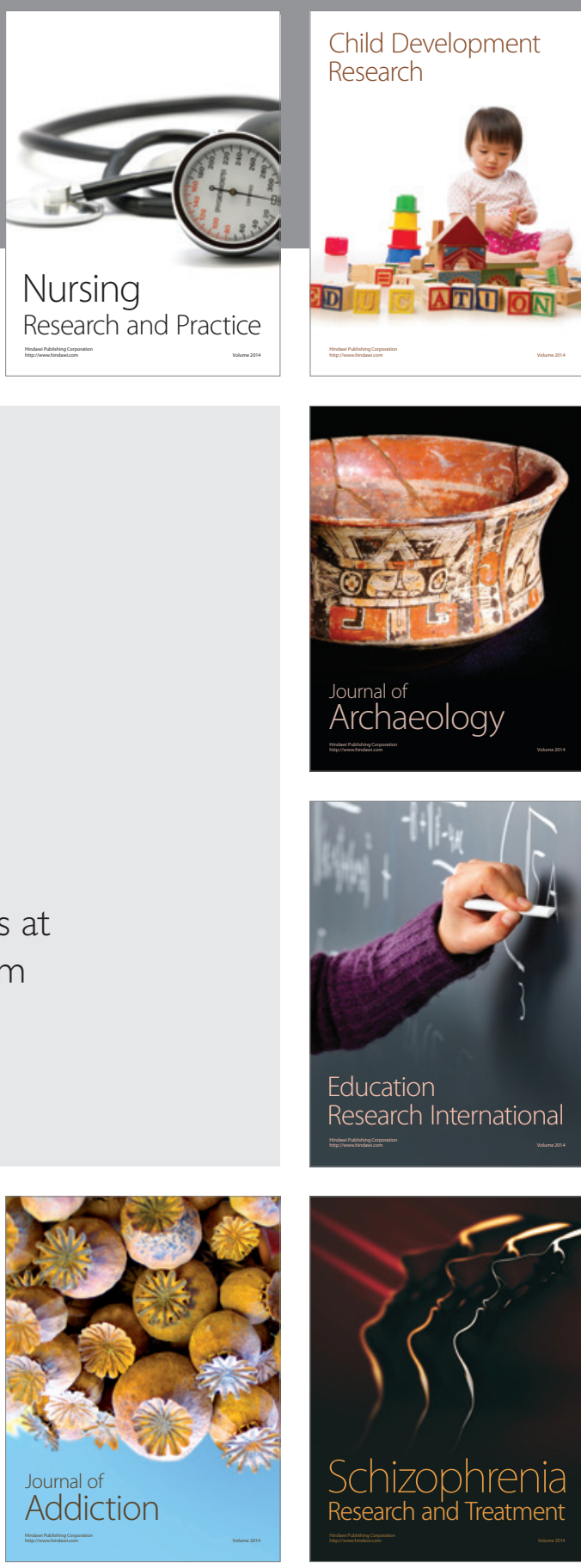

(D)
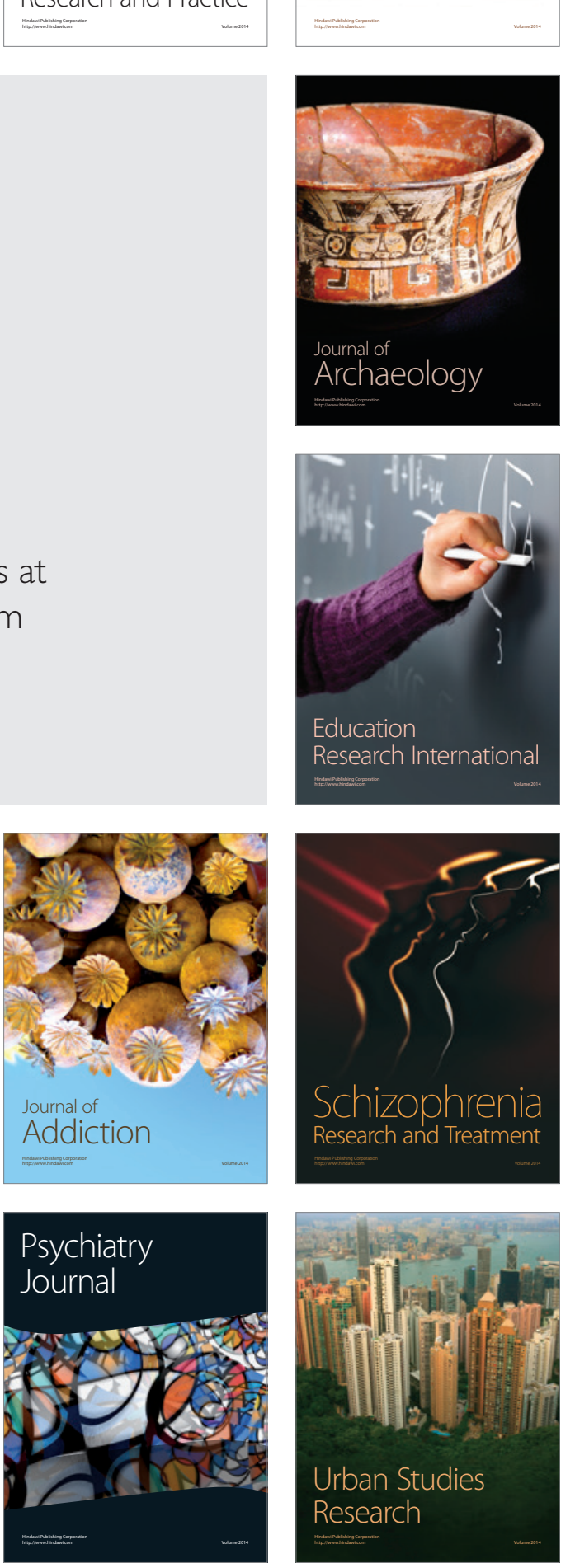